\title{
The accelerator hypothesis: weight gain as the missing link between Type I and Type II diabetes
}

\author{
T. J.Wilkin \\ Department of Medicine, Postgraduate Medical School, Derriford Hospital, Plymouth, UK
}

\begin{abstract}
Blood glucose concentrations are controlled by a loop incorporating two components, the beta cells which secrete insulin and the insulin-sensitive tissues (liver, muscle, adipose) which respond to it. Loss of blood glucose control might result from failure of the beta cells to secrete insulin, resistance of the tissues to its action, or a combination of both. The distinctions between Type I (insulin-dependent) and Type II (non-insulin-dependent) diabetes mellitus are becoming increasingly blurred both clinically and aetiologically, where beta-cell insufficiency is the shared characteristic. The 'Accelerator Hypothesis' identifies three processes which variably accelerate the loss of beta cells through apoptosis: constitution, insulin resistance and autoimmunity.
\end{abstract}

None of the accelerators leads to diabetes without excess weight gain, a trend which the "Accelerator Hypothesis' deems central to the rising incidence of both types of diabetes in the industrially developed world. Weight gain causes an increase in insulin resistance, which results in the weakening of glucose control. The rising blood glucose (glucotoxicity) accelerates beta-cell apoptosis directly in all and, by inducing beta-cell immunogens, further accelerates it in a subset genetically predisposed to autoimmunity. Rather than overlap between two types of diabetes, the 'Accelerator Hypothesis' envisages overlay. Body mass is central to the development and rising incidence of all diabetes. Only tempo distinguishes the 'types'. The control of weight gain, and with it insulin resistance, could be the means of minimising both.

\section{The issue}

Diabetes is currently of two types. Type I (insulin-dependent) diabetes mellitus is an autoimmune disorder of childhood, characterised by acute onset, ketoacidosis and insulin dependency. Type II diabetes is a metabolic disorder of middle-life, slow in onset and non-insulin-dependent.

Received: 15 September 2000 and in revised form: 19 March 2001

Corresponding author: Terence J.Wilkin, MD Department of Medicine, Postgraduate Medical School, Level 7, Derriford Hospital, Plymouth, UK PL6 8DH. E-mail: T.Wilkin@ plymouth.ac.uk

Abbreviations: $Z D F$ zucker diabetic fatty rat, $I C A$ islet cell antibody, $B B$ bio-breeding rat
The definitions need urgent revision. More than half of the patients with Type I diabetes present in adulthood, when their onset is slow and many do not develop acidosis or require insulin for many years [1]. Type II diabetes occurs in teenagers [2], sometimes with keto-acidosis [3], and insulin-dependency frequently ensues given time. Clinically, there is little other than tempo to distinguish two types of diabetes.

\section{The Hypothesis}

The 'Accelerator Hypothesis' argues that Type I and Type II diabetes are one and the same, distinguishable only by their rate of beta cell loss and the accelerators responsible. The first accelerator, a constitutionally (intrinsically) high rate of beta-cell apoptosis, is necessary for diabetes to develop but in itself rarely 
sufficient to cause it. Insulin resistance, the second accelerator, results from weight gain and physical inactivity which further increases the rate of beta-cell apoptosis and accounts for the rising incidence of Type I as well as Type II diabetes in industrially developed societies. Finally, a small and genetically defined subset of patients with both intrinsic lesion and insulin resistance develops beta-cell autoimmunity, the third accelerator. Immune damage in the case of so-called Type I diabetes, when superimposed on slower lesions of the islets shared by both types, merely accelerates the rate of beta-cell loss further. Insulin dependency is the end-stage towards which all diabetes moves and the notions of Type I and Type II, insulin- and non-insulin-dependent, are consequently artificial.

Of the three accelerators, one is intrinsic and two are acquired. Insulin resistance, the second accelerator, is associated with visceral fat mass and is widely believed to explain the epidemic rise of Type II diabetes in the industrially developed world [4]. The 'Accelerator Hypothesis' argues that visceral weight gain is also central to Type I diabetes, as much responsible for its rising incidence as for that of Type II diabetes, and the environmental factor in Type I diabetes that has eluded epidemiology for so long.

The concept of an aetiological link between the two types of diabetes is not new and has been suggested before by the author [5] but the evidence is now stronger. Rather than overlap between the two types of diabetes, the 'Accelerator Hypothesis' envisages overlay. Type I diabetes is the same as Type II except for one essential add-on: immune response.

\section{Pathophysiology of diabetes}

Type I diabetes is associated with autoantibodies and activated lymphocytes which are reactive with betacell antigens [6]. Its course is characterised by a symptomless prediabetic phase whose presence can be inferred from immune markers. Pre-Type I diabetes is a period of accelerated beta-cell loss, whose tempo varies from acute in those who present young to subacute or chronic in those who present later in life [7]. The differences in tempo could be under genetic control, since children who develop Type I diabetes tend to carry different immune-response (HLA) genes from those who develop it later in life $[8,9]$. Beta cell autoimmunity appears to start early in life, insofar as immune markers predictive of future diabetes can be present as early as 9 months of age [10].

Type II diabetes results from a variable combination of insulin resistance and defective insulin response [11]. Blood insulin concentrations are raised, at least initially, but are never sufficient to meet the resistance that entrains them. Like Type I, Type II diabetes also presents after a variable period of pre- diabetes, whose presence can be revealed by high fasting insulin-to-glucose ratios and later by glycosuria or hyperglycaemia in circumstances which temporarily increase insulin resistance - typically pregnancy, thyrotoxicosis or a course of anti-inflammatory steroids. Between 17 and $63 \%$ of women whose glycosuria during pregnancy is attributable to glucose intolerance will subsequently become diabetic, depending on the series quoted [12]. Of these, a proportion (around $20 \%$ according to one study [13]) will develop Type I diabetes, emphasizing the principle to be established here that prediabetes of Type I and Type II differ only in tempo and not in outcome. Both represent a period of accelerated beta cell loss.

Loss of the first phase insulin response to intravenous glucose is a feature characteristic of pre-Type II diabetes [14]. It is not clear whether the abnormality is acquired or an intrinsic disturbance of insulin secretion regarded as necessary, though on its own not usually sufficient, to cause Type II diabetes. The issue is important to a unifying hypothesis, because loss of the first phase insulin response is also characteristic of pre-Type I diabetes, where clearly it is acquired [15].

It has long been recognised that islet cells are both metabolically and immunogenically up-regulated when functionally stressed by rising blood sugar [16]. Beta-cell stress (glucotoxicity) will result from their own low functional mass, or from insulin resistance, both of which reduce the efficiency of feedback control so that the blood glucose rises. These phenomena underpin the rationale for DPT-1, a North American Type I diabetes prevention study which is using lowdose insulin to rest the beta-cell and thereby downregulate the autoimmmune response [17]. At whatever age it emerges, insulin resistance could be expected to increase beta-cell stress and to intensify an autoimmune response in those who are genetically predisposed. The phenomenon of insulin resistance which, as the result of progressively rising body weight, has been largely responsible for reducing the age at presentation of Type II diabetes over recent time might be doing the same for Type I diabetes by promoting the immunological accelerants of beta cell death in a progressively younger age group. If there is little clinically to distinguish two types of diabetes, there is little fundamentally either.

The design of negative feed-back loops ensures that their output is maintained in the face of perturbation and the behaviour of biological control groups is particular in this respect [18]. Blood glucose concentrations do not rise linearly with beta cell loss or with insulin resistance, but only slowly to the point of inflexion where the capacity of the loop becomes saturated, control is lost, and diabetes emerges. All patients who develop diabetes of whichever type progress down the same path of deteriorating control to the point of loop saturation, whether it takes months, years or decades. 


\section{Programmed cell death - apoptosis and phagocytosis}

Apoptosis, or programmed cell death, is a physiological process whereby cell turnover in a tissue is maintained and controlled throughout life [19]. Cells undergoing apoptosis have specific morphological characteristics which distinguish the process from necrosis. So rapid is the removal of apoptotic debris that, however high their turnover, only a small proportion of cells in a tissue can be identified as apoptotic at a given time.

It remains controversial whether the autoimmune events of Type I diabetes are the 'cause' of islet cell damage, or the 'response' to it. I have previously argued, like others before [20], that the immune system evolved originally as a 'house-keeper', programmed to phagocytose the detritus of natural cell-death [21]. It retains that primordial function. From this perspective, autoimmunity will be antigen-driven and specific, its intensity responsive to the rate of apoptosis and modulated by genetic influences. The issues of self-tolerance and its abrogation, which have always made it difficult conceptually to reconcile autoimmunity with a normal immune system, are not at issue where clones expand appropriately to remove apoptotic antigen. Antibodies in this context are the classic immunological adaptors. They link the specific subparticulate molecules to be cleared to non-specific Fc reptors of phagocytic neutrophils, which in turn engulf the complex [22].

Apoptosis has not in the past been considered a process capable of inducing an immune response. Recent studies nevertheless indicate that apoptotic cells can display autoreactive antigen in their blebs, preferentially activate dendritic cells capable of priming tissue-specific cytotoxic $\mathrm{T}$ cells and induce the formation of autoantibodies [23]. Indeed, it has now been shown in animal models that autoimmunity might be triggered by waves of intense apoptosis during the early neonatal period [24]. If the characteristic shared by Type I and Type II diabetes is one of intrinsically excessive beta-cell apoptosis modulated by insulin resistance, the difference between them might be in the immune response genotype, which in Type I diabetes acts to accelerate the beta-cell loss further.

Is there evidence that accelerated beta-cell apoptosis underpins the diabetic state? Like obese humans, Zucker diabetic fatty (ZDF) rats show early compensation (fourfold beta-cell hyperplasia) in response to insulin resistance, followed by decompensation ( $>50 \%$ loss) [25]. In prediabetic and diabetic ZDF islets, apoptosis measured by DNA laddering is increased more than threefold and sevenfold respectively, compared with lean ZDF control rats, showing how inability of the beta-cell mass to respond to mounting insulin resistance leads to loss of glucose control and diabetes [26]. By the time of diagnosis, the beta-cell mass of the spontaneously Type II diabetic Goto-Kakizaki rat falls to half that of its Wistar control [27]. Sucrose-feeding leads to a further reduction of $50 \%$ with clear evidence of accelerated apoptosis.

The effects of hyperglycaemia on the insulin secretory response have also been studied in the desert gerbil Psammomys obesus, which develops nutritiondependent diabetes associated with moderate obesity [28]. Sustained exposure of Psammomys islets to hyperglycaemia in vivo is associated with nuclear disintegration, a raised beta-cell apoptotic index and irreversible loss of insulin secretion [29]. Glucose toxicity is thought to be mediated by oxidative stress due to the activation of cytokines [30] and antioxidants can prevent it [31].

Fibrinogen and C-reactive protein, both acute phase reactants, are increased in seropositive patients with Type II diabetes, who account for more than $12 \%$ of elderly people [32]. Glucose tolerance was worse and the need for medication greater (i.e. the process more advanced) in the autoimmune subgroup. Type II diabetes has been viewed as an acute phase disease of the adaptive immune system in which cytokines released from macrophages, adipose cells or endothelial cells generate oxidative radicals which accelerate beta-cell loss [33, 34]. Among the cytokines, tumour necrosis factor- $\alpha$ (TNF- $\alpha$ ) both increases insulin resistance at the level of the insulin receptor [35] and accelerates beta-cell apoptosis [36].

Tumour necrosis factor- $\alpha$ is secreted in large amounts by visceral (central) fat which [37], distinct from the subcutaneous fat elsewhere in the body, seems to supply the causal link between weight gain, insulin resistance and diabetes [38]. Visceral fat cells also generate fatty acids, which further accelerate beta-cell apoptosis in the rat model [26]. Diet can modulate beta-cell apotosis both directly [26] and apparently by gestational programming of the next generation [39].

Islet tissue from diabetic humans is seldom available for histological examination of its apoptotic state but the United Kingdom Prospective Diabetes Study (UKPDS) was able to monitor islet cell function over 6 years in patients with Type II diabetes [40]. Nearly 3000 patients were allocated intensive therapy either with sulphonylureas or with insulin, the first of which stimulates, while the second rests the beta cell. Glycaemic control nevertheless deteriorated in both groups, to a similar extent and with a progressive loss of insulin response measured formally by glucose clamp. There is one report from Japan of a randomised trial of insulin therapy versus oral hypoglycaemic drugs in an autoimmune (islet cell antibody positive) subset of adult-onset diabetics [41]. The patients treated with insulin preserved C-peptide longer than those receiving oral hypoglycaemics, and lost ICA expression. Others have shown a fall in ICA titre during the administration of parenteral insulin to subjects at 
high risk of developing Type I diabetes [42]. In combination, these observations suggest that accelerated beta-cell loss is intrinsic to all diabetes, inevitable and inexorable. The rate of loss can be accelerated by the oxidative stresses of hyperglycaemia and autoimmunity and slowed, but not returned to normal, by beta-cell rest.

\section{Insulin resistance}

Many theories have sought to account for insulin resistance. The 'Thrifty Genotype Hypothesis' argues for gene selection against muscle proteolysis during an evolutionary history of recurring famine [43, 44]. In contrast, the 'Thrifty Phenotype Hypothesis' [45], which first described an association between low birth weight and insulin resistance, explains the link as a gestational programming of the foetus in response to poor maternal nutrition. More recently, the 'Foetal Insulin Hypothesis' has cited observations in families with maturity onset diabetes of the young (MODY) to illustrate the dependence of foetal growth on the genetics of foetal and maternal insulin secretion [46]. It predicts that a gene or a combination of genes responsible for insulin resistance will be found which leads both to low weight at birth through insulin resistance and to glucose intolerance later in life.

There is a common theme to all three hypotheses: insulin resistance, which might arguably have favoured survival in times of famine, leaves many in today's junk food culture unable to control their blood sugar. None of the theories, however, estimates how much of today's diabetes (the attributable proportion) can be accounted for by congenital insulin resistance already present at birth, nor do these theories explain the rising incidence of Type II diabetes which, according to the logic of all three hypotheses, should by now be stable or falling as nutrition in pregnancy improves and gene selection operates to deselect the less fit. Insulin resistance acquired through lifestyle change is more likely than genes or gestational experience to underlie the recent rise in diabetes and its ever younger presentation.

Importantly for the 'Accelerator Hypothesis', glucose clamp studies 20 years ago showed that non-insulinised patients with autoimmune diabetes were as insulin resistant as metabolic diabetics of comparable glucose tolerance [47]. Furthermore, the rise in proinsulin to insulin ratio, which has long been the hallmark of insulin resistance in pre-Type II diabetes, has more recently been shown to characterise preType I diabetes as well [48]. Most seropositive Type II diabetic adults become Type I more rapidly than those who are seronegative [49], and these observations together provide robust support for the 'overlay' and 'accelerator' concepts. The slower tempo of progression in adults has provided the means of showing that all diabetes is associated with insulin resistance (the second accelerator), that a subgroup advances more rapidly to insulin-dependency as a result of autoimmunity (the third accelerator), and that this subgroup, had it been free of autoimmunity, would have progressed to diabetes in any case, albeit at a later date.

\section{Susceptibility and risk}

Type II diabetes is prevalent in industrially developed societies. It affects up to $30 \%$ of some populations [50], suggesting that susceptibility to diabetes is common, though not universal, inasmuch as some of those at greatest risk (i.e. the pathologically obese) never develop the disease. Concordance in monozygotic twin pairs is widely believed to reflect the genetic contribution to chance and is at around $75 \%$ in Type II diabetes (rising to $95 \%$ if those with glucose intolerance alone are included) [51], but less than $20 \%$ in Type I [52]. However, these figures should be interpreted with caution, as gestational programming might modulate a risk which could readily be misconstrued as susceptibility, and wrongly ascribed to genetics. The correlation between weight at birth, a surrogate for foetal nutrition, and glucose tolerance in adulthood might have more to do with the gestational environment provided by the mother than with the genes she shares with her offspring [46]. This can be resolved only by tracking phenotype with genotype from one generation to the next. Clearly, if insulin resistance and the allele(s) responsible for it were to travel from father to offspring, it would not be appropriate to attribute the insulin resistance to gestational programming.

If both types of diabetes are genetically influenced but to different degrees, a theory which views one as merely a subgroup of the other must consider their different heritability. The high familial concordance of Type II diabetes, a strongly BMI-dependent disorder, can be ascribed to widespread prevalence of the first accelerator gene (implied from the ever-rising prevelance of diabetes in western populations as a whole) coupled with the strong familial association of obesity. The first accelerator gene might respond to Neel's 'thrifty genotype' [44], which has selectively survived the pressures of famine during the course of evolution.

Susceptibility to Type I diabetes, on the other hand, is vested in a small number of relatively uncommon genetic polymorphisms, at least in the young. Thus, around $50 \%$ of Type I diabetes presenting before the age of 16 years occurs in children heterozygous for $H L A D Q B$ alleles which are found together in around only $2 \%$ of the population [53]. A Finnish study of elderly men with Type II diabetes found no 
difference in their frequency of diabetes-associated haplotypes from that associated with Type I diabetes [54]. Thus, glucose intolerance, Type I and Type II diabetes all share specific HLA susceptibility genes. Once the faster tempo that characterizes the development of diabetes in the younger age groups ceases to operate in the elderly, the genotypes and phenotypes of diabetes become indistinguishable. On this basis, the overlay concept of the 'Accelerator Hypothesis' would predict a higher than random prevalence of Type I diabetes among the primary relatives of Type II diabetics [55].

\section{The epidemiology of diabetes}

Over the past 20 years, the incidence of Type II diabetes in the western world has increased dramatically, a pattern which parallels closely the rising incidence of obesity and that of insulin resistance [56]. Furthermore, age at presentation has been falling, such that the incidence of Type II diabetes in American adolescents has increased tenfold, and in Japanese school children 36-fold, within a generation [57]. Rather strikingly, the same pattern of increasing incidence and younger age at presentation has occurred for Type I diabetes over the same time period.

Several studies in Europe show a doubling in incidence of Type I diabetes over the last generation, with a clear shift of presentation to younger age groups, although the data are largely restricted to children and adolescents [58-69]. The incidence of Type I diabetes has been highest around puberty in all populations studied [60, 61]. The earlier peak in girls is consistent with their earlier maturation (Fig.1). The association between diabetes and puberty has never been clearly explained. The hormonal changes of puberty (particularly the rise in growth hormone) could place demands on insulin production which already damaged islets are not able to meet. Again, body mass index rises rapidly during puberty, and with it insulin resistance [63].

If this latter were the correct explanation, the 'Accelerator Hypothesis' would predict a correspondingly earlier presentation of diabetes as the BMI previously associated with puberty is reached at a progressively younger age. It has been reported how, over recent years, the age-at-onset curve for diabetes has risen to include most of early childhood, all but losing its peri-pubertal peak [64]. Others have shown independently that weight gain early in childhood is associated with a higher risk of early Type I diabetes $[65,66]$ and the same appears to be true for Type II diabetes [2]. Most recently, the Childhood Diabetes in Finland Study Group has reported that a relative weight in childhood of more than $120 \%$ is associated with a more than twofold greater risk of developing Type I diabetes [68]. These observations provide im- portant support for the 'Hypothesis'. They point to a central role for body mass and by implication for insulin resistance in the development of Type I and Type II diabetes.

Seasonality of birth among those with Type I diabetes has been reported though not consistently [68, 69]. The predominance of winter births has led to the suggestion that viral infection during late gestation might trigger autoimmune insulitis but a seasonal variation of birth weight has not previously been considered as an alternative explanation. The prevalence of obesity later in life has recently been shown to vary with the month of birth, the association being strongest among those born early in the year and after cold winters [70].

There are several reports that children exposed to (cow's) milk formula feeds before the third month of life are at greater risk of developing Type I diabetes $[71,72]$. Evidence from the spontaneously Type I diabetic $\mathrm{BB}$ rat that removal of intact cow's milk protein from its chow can prevent the onset of autoimmune diabetes [73], although now controversial [74], has led many to search for an immunological explanation. Most recently, human trials of Nutramigen, an infant formula which contains casein-hydrolysates rather than intact cow's milk protein, have been piloted. However, interpretation of the epidemiological evidence incriminating cow's milk protein has not considered the body mass differences between breastfed and bottle-fed infants. Formula-fed infants are heavier than those who are breast-fed [63], and the differences are due to a greater fat mass [75]. The differences in weight gain are a confounder and their implications for insulin resistance, oxidative stress and beta-cell loss merit attention.

\section{Body mass: the elusive 'trigger’ of Type I diabetes}

Type I diabetes at onset is associated with weight loss, which is also of course true for Type II diabetes when it enters the corresponding phase of beta-cell decompensation. Diabetes is the end-result of a pathological process, not the process itself. The process which leads to Type I diabetes begins early in life $[10,11]$, but insulin resistance present at birth, whether it proves to be genetic, acquired in utero or a combination of the two, cannot explain the exponential rise in diabetes experienced over the past generation. The rise is almost certainly related to the secular increase in body weight which has occurred over the same period [76] and to the reduction in physical activity which has accompanied it [77]. If the rising incidence and earlier presentation of diabetes were to be explained by an ever heavier population at all ages, weight gain would have as much a role in the demography changes of Type I diabetes as it does in that of Type II diabetes. 


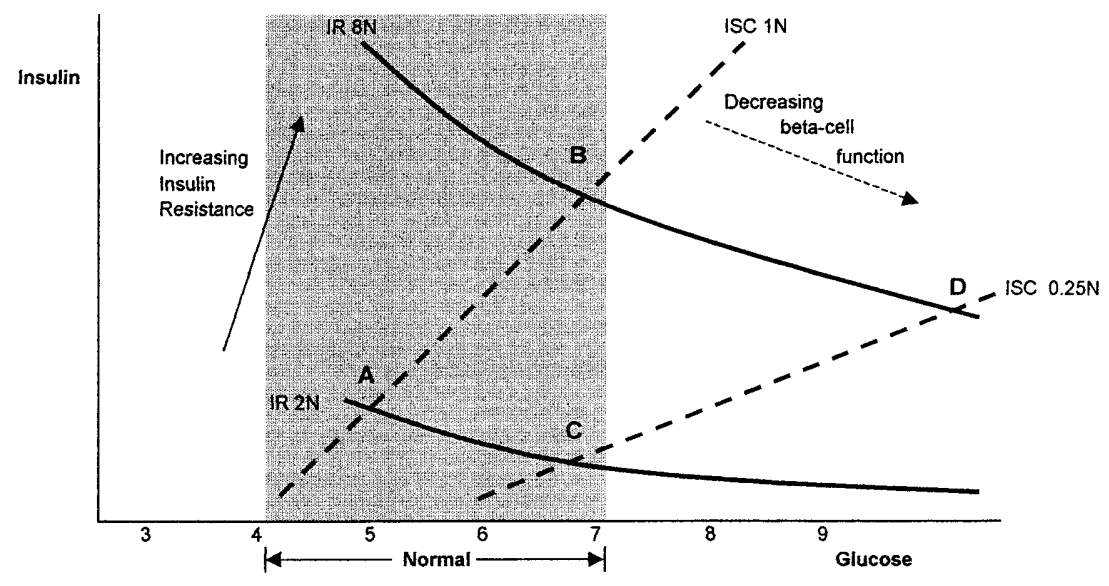

Fig. 1. The association between insulin resistance (IR) and insulin secretory capacity (ISC, beta cell mass) in the control of blood glucose (modified after Matthews et al.) [62]. Four subjects, with either mild or severe IR, are depicted at the intersections of curves which define the relation between the plasma concentrations of glucose and insulin at two values of IR (twice normal and eight times normal) and of ISC (normal and one-quarter normal). Subject A has an IR twice normal ( $2 \mathrm{~N}$ ), but an ISC $100 \%$ (1 N) which is sufficient to meet it. Fasting blood sugar control is normal. Subjects $\mathrm{B}$ and $\mathrm{C}$ are decompensating, but for different reasons. In $\mathrm{B}$, IR is now eight times normal $(8 \mathrm{~N})$, but ISC still $100 \%(1 \mathrm{~N})$. This depiction characterises the pre-Type II diabetic, with high circulating insulin concentrations but deteriorating glucose tolerance. In $\mathrm{C}$, IR is again twice normal $(2 \mathrm{~N})$, but ISC markedly reduced at $25 \%(0.25 \mathrm{~N})$, typical of the pre-Type I diabetic. Subject D has established diabetes resulting from a combination of high IR and low ISC, which has deteriorated compared with subject $\mathrm{B}$, and no longer sufficient to maintain blood sugar control

Ascribing the rising incidence of Type I diabetes to metabolic, rather than to immunological, factors has new and important implications. Clinical research over the past 20 years has focused almost exclusively on exogenous factors (viruses, toxins, allergens) deemed able to initiate, facilitate or intensify autoimmune damage to the beta cell. Although many have been proposed [78], none has been confirmed. The prevalence of obesity meanwhile has doubled. Insulin resistance, resulting from a combination of obesity and physical inactivity, is a serious candidate for the 'elusive' environmental factor responsible for the rising incidence of Type I diabetes and, as such, a true accelerator.

\section{Diabetes: I and II, or one and the same?}

The rise in incidence of diabetes in 'westernised' countries over recent time has occurred over a period too brief for changes in the gene pool to exert such an influence. Similarly, there is no evidence of falling birth weight over the same period to suggest a dete- rioration in foetal quality with its attendant risk of insulin resistance - indeed, birth weights have risen. More likely, it is the progressive increase in body weight, with the rising prevalence of obesity at all ages over the past 20 years, which is responsible.

The 'Accelerator Hypothesis' at its simplest can be reduced to the unfavourable interplay of two phenomena: disturbed beta-cell apoptosis and insulin resistance (Fig. 1). Apoptosis occurs throughout life at a variable rate but is intrinsically higher in those who are susceptible to diabetes. Many people of normal body mass, despite intrinsically rapid beta-cell apoptosis, never develop glucose intolerance because insulin secretory reserve remains sufficient in such circumstances to maintain control of blood glucose concentrations. However, insulin resistance, whether present at birth or acquired through the accumulation of visceral fat during life, makes demands on insulin secretion which in some cannot be met.

Autoimmune damage of the beta cells is an additional factor, restricted by genotype to small and independent minorities of the intrinsically diabetessusceptible and non-susceptible populations alike. At its most aggressive, autoimmunity might be sufficient to cause diabetes of itself, though an accelerator different from insulin resistance would be needed to account for the increase in apoptosis which provokes it. The 'Accelerator Hypothesis' predicts that in older patients, where beta-cell auto-reactivity is less aggressive, those with islet-cell autoimmunity most likely to develop diabetes will already have the diabetic phenotype - a low beta cell mass and high insulin resistance. Those who do not could be expected to remain seropositive but healthy, to succumb only as and when the intrinsic beta-cell mass wanes and/or insulin resistance rises with the corpulence of advancing age.

Tempo alone, it is argued, distinguishes what in the past have been described as two separate types of diabetes. The three phases in the progression to overt diabetes - pre-diabetes, chemical diabetes and clinical diabetes - can all be identified in both types, differing only (but sometimes substantially) in their re- 
lative duration. Not to take account of these differences in tempo of the three phases will make it conceptually difficult to regard as equivalent two diabetic states where insulin is needed from the outset in one, but only (if ever) after a long period of clinical diabetes in the other. The requirement for insulin is nevertheless reached at exactly corresponding points in the progression of pre-diabetes in both cases - the point of inflexion in the control curve, where the loop becomes saturated and glucose control is lost [18]. All people with diabetes pass through this point to insulin-dependence - some do so very quickly, but others might not reach it in a lifetime.

A hypothesis postulating body mass as a primary risk factor in the aetiology of Type I, and Type II, diabetes is novel but eminently testable. It must first be established whether people with pre-Type I diabetes are insulin-resistant compared with healthy control subjects, and whether the greater body mass recorded during the infancy of those who later develop Type I diabetes is sufficient to account for the resistance. Metabolic studies in Type I diabetics have been more concerned with beta-cell function and have measured the insulin response to glucose rather than the glucose response to insulin. If they prove to be more insulin-resistant, it should be determined whether the pre-Type I diabetics carry more visceral fat before decompensation. Finally, it must be established whether strategies to reduce the second accelerator (insulin resistance) in those at risk from Type I diabetes, through weight loss, metformin, or one of the new thiazolidinediones [79] is paralleled by a deceleration in the third - autoimmune damage to the beta cells.

The notion that Type I diabetes merely represents the accelerated development of Type II diabetes is important if it implies that strategies currently on trial to remove the immunological accelerator of Type I diabetes (e.g. DPT-1 [17]) leave unchanged the insulin resistance which provoked it and the risk of later developing Type II diabetes. Conversely, the control of weight gain, and with it insulin resistance, could be the fundamental means of minimising the risk of both.

\section{References}

1. Molbak AG, Christau B, Marner B, Borch-Johnsen, Nerup J (1994) Incidence of insulin-dependent diabetes in age groups over 30 years in Denmark. Diabet Med 11: 650-655

2. Rosenbloom AL, Joe JR, Young RS, Winter WE (1999) Emerging epidemic of Type II diabetes in youth. Diabetes Care 22: 345-354

3. Aizawa T, Funase Y, Katakura M et al. (1997) Ketosis-onset diabetes in young adults with subsequent non-insulindependency, a link between IDDM and NIDDM? Diabet Med 14: 989-991

4. Zimmet P (2000) Globalization, coca-colonization and the chronic disease epidemic: can the Doomsday scenario be averted? J Intern Med 247: 301-310
5. Wilkin TJ (1992) Early nutrition and diabetes mellitus (Editorial) BMJ 306: 283-284

6. Atkinson MA, Maclaren NK (1994) The pathogenesis of insulin-dependent diabetes mellitus. N Engl J Med 331: $1428-1436$

7. Eisenbarth GS, Gianani R, Yu L et al. (1998) Dual-parameter model for prediction of type I diabetes mellitus. Proc Assoc Am Physicians 110: 126-135

8. Demaine AG, Hibberd ML, Mangles D, Millward BA (1995) A new marker in the HLA class I region is associated with the age at onset of IDDM. Diabetologia 38: 623-628

9. Caillat-Zucman S, Garchon HJ, Timsit J et al. (1992) Agedependent HLA genetic heterogeneity of Type I insulindependent diabetes mellitus. J Clin Invest 90: 2242-2250

10. Ziegler AG, Hummel M, Schenker M, Bonifacio E (1999) Autoantibody appearance and risk for development of childhood diabetes in offspring of parents with Type I diabetes: the 2-year analysis of the German BABYDIAB Study. Diabetes 48: 460-468

11. Turner RC, Holman RR, Matthews DR, Peto J (1982) Relative contributions of insulin deficiency and insulin resistance in maturity-onset diabetes. Lancet i: 596-598

12. Kjos SL, Buchanan TA (1999) Gestational diabetes merllitus. New Engl J Med 341: 1749-1756

13. Damm P, Kuhl C, Buschard K et al. (1994) Prevalence and predictive value of islet cell antibodies and insulin autoantibodies in women with gestational diabetes. Diabet Med 11: $558-563$

14. Kadowaki T, Miyake Y, Hagura R et al.(1984) Risk factors for worsening to diabetes in subjects with impaired glucose tolerance. Diabetologia 26: 44-49

15. Mirena S, Savola K, Kulmala P, Akerblom HK, Knip M (1999) Staging of preclinical Type I diabetes in siblings of affected children. Childhood Diabetes in Finland Study Group. Pediatrics 104: 925-930

16. Bjork E, Kampe O, Karlsson FA et al. (1992) Glucose regulation of the autoantigen GAD65 in human pancreatic islets. J Clin Endocrinol Metab 75: 574-576

17. Rabinovitch A, Skyler JS (1998) Prevention of Type I diabetes. Med Clin North Am 82: 739-755

18. Wilkin TJ (1997) Endocrine feedback control in health and disease. In: EE Bittar, N Bittar (Eds) Principles of Medical Biology molecular and cellular endocrinology Vol 10A. JAI Press Inc, Greenwich CT pp1-28

19. Mauricio D, Mandrup-Poulsen T (1998) Apoptosis and the pathogenesis of IDDM: a question of life and death. Diabetes 47: 537-543

20. Grabar P (1983) Autoantibodies and the physiological role of immunoglobulins. Immunol Today 4: 337-340

21. Wilkin TJ (1989) Autoimmunity: attack or defence? Autoimmunity 3: 57-73

22. Roitt I, Brostoff J, Male D (1995) Immunology. Churchill Livingstone, London pp 1.5-1.6

23. Rovere P, Vallinoto C, Bondanza A et al. (1998) Cutting edge: bystander apoptosis triggers dendritic cell maturation and antigen-presenting function. J Immunol 161: $4467-4471$

24. Trudeau JD, Dutz JP, Arany E, Hill DJ, Fieldus WE, Finegood DT (2000) Neonatal cell apoptosis: a trigger for autoimmune diabetes? Diabetes 49: 1-7

25. Shimabukuro M, Zhou YT, Levi M, Unger RH (1998) Fatty-acid induced cell apoptosis: a link between obesity and diabetes. Proc Nat Acad Sci USA 95: 2498-2502

26. Pick A, Clark J, Kubstrup C et al. Role of apoptosis in failure of -cell mass compensation for insulin resistance and cell defects in the male Zucker fatty rat. Diabetes 47: 358-364 
27. Koyama M, Wada R, Sakuraba H, Yagihashi S (1998) Accelerated loss of islet cells in sucrose-fed Goto-Kakizaki rats, a genetic model of non-insulin dependent diabetes mellitus. Am J Pathol 153: 537-545

28. Donath MY, Gross DJ, Cerasi E, Kaiser N (1999) Hyperglycaemia - induced-cell apoptosis in pancreatic cells of Psammomys obesus during development of diabetes. Diabetes 48: 738-744

29. Bar-On H, Ben-Sasson R, Ziv E, Arar N, Shafrir E (1999) Irreversibility of nutritionally induced NIDDM in Psammomys obesus is related to cell apoptosis. Pancreas. 18: 259-265

30. Olejnicka BT, Dalen H, Brunk UT (1999) Minute oxidative stress is sufficient to induce apoptotic death of NIT-1 insulinoma cells. APMIS 107: 747-761

31. Kaneto H, Kajimoto Y, Miyagawa J et al. (1999) Beneficial effects of anti-oxidants in diabetes: possible protection of pancreatic cells against glucose toxicity. Diabetes 48: 2398-2406

32. Pietropaolo M, Barinas-Mitchell E, Pietropaolo SL, Kuyller L, Trucco M (2000) Evidence of islet cell autoimmunity in elderly patients with Type II diabetes. Diabetes 49: 32-38

33. Fearon DT, Locksley RM (1996) The instructive role of innate immunity in the acquired immune response. Science 272: 50-54

34. Pickup JC, Mattock MB, Chusney GD, Burt D (1997) NIDDM as a disease of the innate immune system: association of acute phase reactants and interleukin- 6 with metabolic syndrome X. Diabetologia 40: 1286-1292

35. Hotamisligil GS (1999) The role of TNFalpha and TNF receptors in obesity and insulin resistance. J Intern Med 245: $621-625$

36. Ishizuka N, Yagui K, Tokuyama Y et al. (1999) Tumour necrosis factor alpha signaling pathway and apoptosis in pancreatic cells. Metabolism 48: 1485-1492

37. Barzilai N, She L, Liu BQ et al. (1999) Surgical removal of visceral fat reverses hepatic insulin resistance. Diabetes 48: 94-98

38. Bjorntorp P (1997) Body fat distribution, insulin resistance, and metabolic diseases. Nutrition 13: 795-803

39. Petrik J, Reusens B, Arany E et al. (1999) A low protein diet alters the balance of islet replication and apoptosis in the foetal and neonatal rat and is associated with a reduced expression of insulin-like growth factor II. Endocrinology 140: 4861-4873

40. UK Prospective Diabetes Study Group (1995) UK prospective study 16 . Overview of six years' therapy of Type II diabetes. Diabetes 44: 1249-1258

41. Yu 1, Eisenbarth GS (1998) Immunology of Type I diabetes and related endocrine disorders.In: Klibanski A, Biller BMK (eds) Clinical endocrinology update. The Endocrine Society Press, Bethesda pp258-266

42. Rodriguez-Villar C, Conget I, Casamitjana R, Ercilla G, Gomis R (1999) Effects of insulin administration in a group of high-risk, non-diabetic, first degree relatives of Type I diabetic patients: an open pilot trial. Diabet Med 16: 160-163

43. Neel JV (1962) Diabetes mellitus: a 'thrifty' genoype rendered detrimental by 'progress'? Am J Hum Genet 14: 353-362

44. Reaven GM (1998) Hypothesis: muscle insulin resistance is the ('not so') thrifty genotype. Diabetologia 41: 482-484

45. Hales CN, Barker DJP (1992) Type II (non insulin-dependent) diabetes: the thrifty phenotype hypothesis. Diabetologia 35: 595-601

46. Hattersley AT, Tooke JE (1999) The fetal insulin hypothesis: an alternative explanation of the association of low birth weight with diabetes and vascular disease. Lancet 353: 1789-1792

47. Gray RS, Borsey DQ, Irvine WJ, Duncan LJ, Clarke BF (1983) Non-insulin-treated ICA positive diabetics are equally insulin-resistant. Diabetes Metab 9 : 292-296

48. Rodriguez-Villar C, Conget I, Casamitjana R, Vidal J, Manzanares JM, Gomis R (1997) High proinsulin levels in late pre-IDDM stage. Diabetes Res Clin Pract 37: 145-148

49. Turner R, Stratton I, Horton Vet al. (1997) UKPDS 25: autoantibodies to islet-cell cytoplasm and glutamic acid carboxylase for prediction of insulin requirement in Type II diabetes. UK prospective diabetes Study Group. Lancet 350: 1288-1293

50. Zimmet PZ, McCarty DJ, de Courten MP (1997) The global epidemiology of non-insulin-dependent diabetes mellitus and the metabolic syndrome. J Diabetes Complications 11: $60-68$

51. Medici F, Hawa M, Ianari A, Pyke DA, Leslie RD (1999) Concordance rate for Type II diabetes mellitus in monozygotic twins: an actuarial analysis. Diabetologia 42: 146-150

52. Kaprio J, Tuomilehto J, Koskenvuo M et al. (1992) Concordance for Type I (insulin-dependent) and Type II (non-insulin-dependent) diabetes mellitus in a population-based cohort of twins in Finland. Diabetologia. 35: 1060-1067

53. Deschamps I, Khalil I (1993) The role of DQ alpha-beta heterodimers in genetic susceptibility to insulin-dependent diabetes. Diabetes Metab Rev 9: 71-92

54. Tuomilheto-Wolf E, Tuomilheto J, Hitman GA et al. (1993) Genetic susceptibility to non-insulin dependent diabetes mellitus and glucose intolerance are located in the HLA region. BMJ 307: 155-159

55. Dahlquist G, Blom L, Tuvemo T, Nystrom L, Sandstrom A, Wall S (1989) The Swedish childhood diabetes study-results from a nine year case register and a one year case-referent study indicating that Type I (insulin-dependent) diabetes mellitus is associated with both Type II (non-insulindependent) diabetes mellitus and autoimmune disorders. Diabetologia 32: 2-6

56. National Task Force on the Prevention and Treatment of Obesity (2000) Overweight, obesity, and health risk. Arch Intern Med 160: 898-904

57. Kitagawa T, Owada M, Urakami T, Yamauchi K (1998) Increased incidence of non-insulin dependent diabetes mellitus among Japanese schoolchildren correlates with an increased intake of animal protein and fat. Clin Pediatr (Phil) 37: 111-115

58. Onkamo P, Vaananen S, Karvonen M, Tuomilehto J (1999) Worldwide increase of Type I diabetes - analysis of the data on published incidence trends. Diabetologia 42: 1395-1403

59. Zhao HX, Stenhouse E, Soper C et al. (1999) Incidence of childhood-onset Type I diabetes mellitus in Devon and Cornwall, England, 1975-1996. Diabet Med 16: 1030-1035

60. Akerblom HK, Reunanen A (1985) The epidemiology of insulin-dependent diabetes mellitus (IDDM) in Finland and in northern Europe. Diabetes Care 8 [Suppl 1]:10-16

61. Staines A, Bodansky HJ, Lilley HE, Stephenson C, McNally RJ, Cartwright RA (1993) The epidemiology of diabetes mellitus in the United Kingdom: the Yorkshire Regional Childhood Diabetes Register. Diabetologia. 36: 1282-1287

62. Matthews DR, Hosker JP, Rudenski AS et al. (1985) Homeostasis model assessment: insulin resistance and beta-cell function from fasting plasma glucose and insulin concentrations in man. Diabetologia 28: 412-419

63. Moran A, Jacobs DR Jr, Steinberger J et al. (1999) Insulin resistance during puberty: results from clamp studies in 357 children. Diabetes 48: 2039-2044 
64. Tuomilehto J, Virtala E, Karvonen M et al. (1995) Increase in incidence of insulin-dependent diabetes mellitus among children in Finland. J Epidemiol 24: 984-992

65. Johansson C, Samuelsson U, Ludvigsson J (1994) A high weight gain in early life is associated with an increased risk of Type I (insulin-dependent) diabetes mellitus. Diabetologia 37: 91-94

66. Hypponen E, Kenward MG, Virtanen SM et al. (1999) Infant feeding, early weight gain and risk of Type I diabetes. Childhood diabetes in Finland (DiME) Study Group. Diabetes Care 22: 1961-1965

67. Hypponen E, Virtanen SM, Kenward MG, Knip M, Akerblom HK (2000) Obesity, increased linear growth, and risk of Type I diabetes in children. Childhood Diabetes in Finland Study Group. Diabetes Care 23: 1755-1760

68. Rothwell PM, Staines A, Smail P, Wadsworth E, McKinney P (1996) Seasonality of birth of patients with childhood diabetes in Britain. BMJ 312: 1456-1467

69. Jongbloet PH, Groenewould HMM, Hirasing RA, Van Buuren S (1998) Seasonality of birth in patients with childhood diabetes in the Netherlands. Diabetes Care 21: 190-191

70. Phillips DI, Young JB (2000) Birth weight, climate at birth and the risk of obesity in adullt life. Int J Obes Relat Metab Disord 24: 281-287
71. Atkinson MA, Ellis TM (1997) Infants' diets and insulindependent diabetes: evaluating the "cows' milk hypothesis" and a role for anti-bovine serum albumin immunity. J Am Coll Nutr 16: 334-340

72. Kotanko P (1997) Type I diabetes and the "milk hypothesis". Diabetes Care 20: 233-234

73. Daneman D, Fishman L, Clarson C, Martin JM (1987) Dietary triggers of insulin-dependent diabetes in the BB rat. Diabetes Res 5: 93-97

74. Malkani S, Nompleggi D, Hansen JW, Greiner DL, Mordes JP, Rossini AA (1997) Dietary cow's milk protein does not alter the frequency of diabetes in the BB rat. Diabetes 46: 1133-1140

75. Dewey KG, Heinig MJ, Nommsen LA, Peerson JM, Lonnerdal B (1993) Breast-fed infants are leaner than formula-fed infants at $1 \mathrm{y}$ of age: the DARLING study. Am J Clin Nutr 57: 140-145

76. Seidell JC, Flegal KM (1997) Assessing obesity: classification and epidemiology. BMed Bull 53: 238-252

77. Prentice AM, Jebb SA (1995) Obesity in Britain: gluttony or sloth? BMJ 311: 427-429

78. Dahlquist G (1998) The aetiology of Type I diabetes: an epidemiological perspective. Acta Paediatr Suppl 425: 5-10

79. Day C Thiazolidinediones. Diabet Med 16: 179.192 